\section{Aether, Fields \& Energy Dynamics in Living Bodies - Part II}

\author{
K. E. Thorp ${ }^{1}$, James A. Thorp ${ }^{2 \star}$, Paul R. Walker ${ }^{3}$
}

'Department of Radiology, Sparrow Health System, Lansing, MI 2Department of Obstetrics and Gynecology, Division of Maternal Fetal Medicine, Sisters of St. Mary's Health System, St. Louis, MO. ${ }^{3}$ BSME, MSEE
Submitted: 04 November 2021
Approved: 14 November 2021
Published: 15 November 2021

Address for correspondence:

James A. Thorp, Department of Obstetrics and Gynecology, Division of Maternal Fetal Medicine, Sisters of St. Mary's Health System, St. Louis, MO

How to cite this article: Thorp KE, Thorp JA, Walker PR. Aether, fields \& energy dynamics in living bodies - Part II. G Med Sci. 2021; 2(6): 001-020.

https://www.doi.org/10.46766/thegms.medphys.21110401

Copyright: @ 2021 K. E. Thorp, James A. Thorp, Paul R. Walker. This is an Open Access article distributed under the Creative Commons Attribution License, which permits unrestricted use, distribution, and reproduction in any medium, provided the original work is properly cited.

\section{Introduction}

In the first part of the article we examined the historical dimensions of the aether concept, from Aristotle through Newton, Huygens, Young, Maxwell, Einstein, Dirac and, finally, Wheeler and saw its evolution from an insensible, transparent substance effecting the circular motions of heavenly bodies, to an indispensable omnipresent medium accounting for all manifest phenomena: matter, mass and gravity, open space, as well as primary energetic phenomena like light, electricity, and magnetism. Aether is the means by which something comes out of 'nothing.'

We focused on Wheeler's trailblazing synthesis which, for the first time, provides an integrated account of aether field dynamics, i.e., the generation of force and motion, through the interaction of its two primary modalities, dielectricity and magnetism. Electricity, the third force, derives from the interaction between dielectricity and magnetism. Wheeler's aether-based cosmology debunks all the atomistic theories that contemporary science holds so dear, just as Aristotle's defense of the continuum and refutation of empty space did in the $4^{\text {th }}$ century BC. Atomism has never been a viable doctrine except in the minds of its adherents.

Wheeler's work centers largely on the interaction of aether-derived forces but doesn't examine the pivotal role that water plays in mediating field effects in living bodies and at the planetary level. This is relevant since water composes about $60 \%$ of living bodies and covers about $70 \%$ of the earth's surface. It is not possible to describe dielectricity, magnetism, electricity or light in natural systems without considering their interactions with water.

In the $5^{\text {th }}$ century BC Greek philosopher Empedocles proposed the four classical elements, earth, water, air and fire, as the basis for all natural terrestrial phenomena to which Aristotle, a century later, added a fifth, the aether. By the mid-20 $0^{\text {th }}$ century atomistic science had identified nearly 100 naturally occurring atomic elements with water being regarded simply as a composite of hydrogen and oxygen. And yet over the past century physical scientists have identified dozens of so-called anomalous properties of water not readily explainable on the basis of its chemical attributes. This has led some to question whether, in fact, it is a distinct element [1].

As we will see, the functional effects of the body's energy system are mediated via the anomalous 'elemental' properties of water. And planetary phenomena like the diurnal tide cycles, which scientists attribute to lunar gravitational effects, arise from interactions between water and the conjoined dielectric/magnetic field.

In this second part we examine dynamics of the three primary aether modalities in the water-body: first, the magnetic, which takes origin in the cardiovascular system; secondly, the radiant, related to ambient light-fall upon the body from the outside or that generated internally, and flows as organized currents in interstitial water; and 
the dielectric, which predominates in the intracellular fluid spaces, mediated by ion currents, and is involved in the generation and maintenance of cell structure and molecular energy metabolism.

\section{Heart \& Magnetic Field}

In his description of the circulation of the blood in 1628, William Harvey made what some regard to be one of the greatest discoveries in the history of medicine. But it is overlooked that in the same treatise in which he announced his discovery, Harvey introduced a monumental error that obstructed advancement of medical knowledge for 350 years.

In Anatomical Studies on the Motion of the Heart and Blood Harvey comments, 'the heart does not act in diastole but in systole for only when it contracts is it active,' and later, 'likewise, it is not true, as commonly believed that the heart by its own action or distention draws blood into the ventricles. When it moves and contracts it expels blood, when it relaxes and is quiet it receives blood' [2]. In making this deliberation Harvey contradicted a line of accepted medical thought that went back nearly 1500 years to Roman physician Galen who claimed diastole was the primary phase of the cardiac cycle during which the heart generated a suction force that drew blood forward through the blood vessels [3].

In the 1980 s reports described negative intraventricular pressures in the early diastolic phase of the heart cycle which, researchers soon realized, must account for diastolic filling and the forward movement of blood [4, 5]. A 1986 article in Scientific American entitled The Heart as a Suction Pump proposed a new diastolic-centered model of cardiac function [6]. A spate of studies followed in support of active dilation and by the late 1980 s researchers had coined the term 'diastolic dysfunction' to designate a growing number of pathologic conditions associated with impaired outward movement of the ventricle [7, 8]. In the mid-1990s a paper refuted Harvey's propulsion theory of heart function [9]. Numerous studies describe spiral arterial flow currents which can only be explained on the basis of a suction force [10-23].

How can we understand the generation of force and motion in the cardiovascular system? Based on our knowledge of aether effects, the active outward expansion of the ventricle and suctional force must be taken as prima facie evidence of magnetic field dynamics for, as Wheeler points out, magnetism is the only aether modality to possess 3-D spatiality. What are the mechanisms at play in the generation of this field?

In his descriptions of the heart's motions Harvey observed that during systole it became 'constricted all over, thicker in its walls and smaller in its ventricles' and described 'a peculiar side-wise turning . . . as if it twists slightly on itself in performing its work.' Decades later Richard Lower likened this twisting motion to the wringing of a wet cloth. This peculiar torsional deformity continues to attract researchers' attention. The most striking evidence regarding the means by which the heart generates the magnetic field has surfaced in recent decades.

The twist or torsional deformity of the left ventricle (LV) represents the difference between the clockwise and counterclockwise rotatory motions of the apex and base of the heart. During systolic contraction the apex of the $\mathrm{LV}$ (as viewed from the apex) twists in a counterclockwise motion while the base (which lies at the atrio-ventricular plane) rotates in a clockwise direction. During diastolic expansion these motions reverse and the base turns counterclockwise while the apex twists clockwise [24-32]. Such inverse spiral motions between systole and diastole conform to the counterspatial and spatial influences of the dielectric and magnetic fields. Similarities are even more striking when evidence is examined further.

In recent decades pathologists discovered that the heart is a continuous sheet of muscle cells known as the ventricular myocardial band which extends from the root of the pulmonary artery to the root of the aorta. During embryonic development the muscle band becomes twisted into a helical loop. By carefully teasing apart overlapping layers along cleavage planes the ventricular wall can be unwrapped and fully exposed [33, 34].

One side of the band extends from the root of the pulmonary artery to the apex of the heart and forms parts of the RV and LV walls. At the apex the muscle fiber band makes an abrupt $180^{\circ}$ twist, forming a spiral loop known as the vortex cordis, and then continues into the aorta as the LV wall. Contraction of this uninterrupted counterdirectional loop of muscle fibers during systole produces the characteristic wringing movement described by Harvey and Lower 350 years ago.

The systolic twisting action is also affected by the inverse spiral anatomy of cardiac myofibrils: In the wall of the heart the spin of the fibers gradually morphs from a righthanded helical configuration near the ventricular cavity to a left-handed helix at the outer wall, resembling the mirror-image spin symmetry of the magnetic field. Due to the differential surface area of the inner and outer walls the base and apex rotate in opposite directions.

As scientists have yet to integrate aether dynamics into their mechanical framework they claim that differential twist deformities between the inner and outer muscle fiber networks, rather than inducing torsional stress at the aether plane, produce 'storage of potential energy' whatever that might mean. Thus, active dilation of the ventricle which, à la Harvey they call the relaxation phase, is ostensibly due to a 'restoring force' that induces elastic recoil of the ventricular wall with resultant suction of 
blood into its chamber. This explanation is absurd and completely unfounded.

What happens in LV systolic contraction is identical to what happens in the generation of an external magnetic field secondary to electrification of a ferrous object. In animal dissections Galen observed that when the heart was cut out it continued to dilate and contract; this is called cardiac automaticity. By the same token, transplanted hearts continue to function in recipients even though the conduction system has been severed. Accordingly, there has been much debate concerning the role of the cardiac nerves in the induction of systole. Evidence indicates that electrical currents don't induce ventricular contraction but, instead, generate an external magnetic field.

To appreciate this, systole and diastole must be viewed from a dynamic perspective. Systole, during which the heart contracts, muscle fibers thicken, and the ventricles decrease in size, is the dielectric counterspatial phase of the cardiac cycle. Diastole, during which the ventricular chambers expand, the walls become thinner and balloon outwardly, is the magnetic spatial phase of the cycle. The flow of electrical currents through nerves and heart muscle during systole saturates the dielectric field inducing nuclear precession in cardiac muscle iron stores. As a consequence of this the 3-D magnetic field is repelled by the dielectric field into the ventricle causing its dilation. In the cardiovascular system, aether effects occur sequentially rather than simultaneously. Systole and diastole are dynamic oscillational behaviors whose frequencies are discernible by empirical observation.

The most compelling evidence for this is seen in the spiral flow currents of large and medium sized arteries. No explanation for such flow patterns suffices except a suction force. Based on the 'elastic recoil' hypothesis this force should entirely dissipate once dilation of the ventricle is complete and thus it cannot explain helical currents in arteries. Studies show spiral currents in the aorta during ventricular contraction indicating dominance of the suction force over the force that propels blood forward.

As Galen pointed out, if the entire arterial system dilated all at once, there would be no continuous movement of blood. The very same mechanism by which blood is drawn forward into the ventricles must necessarily be in play sequentially in the arterial system, which manifests in periodic (oscillational) pulse waves mediated by endothelial-dependent dilation of the arterial wall and release of nitric oxide. Periodic outward dilation of the arterial wall, like diastole, is a result of an aether-derived magnetic force which, in this instance, originates in the blood. This blood-borne energy field forms the basis of Galen's humoral system of medicine just as it accounts for the ischemic preconditioning phenomenon which has baffled cellular and molecular biologists for nearly four

\section{decades.}

Given that both dilation of the ventricular and arterial walls as well as spiral flow currents are manifestations of the same force it is axiomatic that as generation of the magnetic field deteriorates both parameters are adversely impacted. One cannot change without affecting the other. The most widely detailed aspect of magnetic field deterioration concerns the phenomenon of diastolic dysfunction, the loss of outward wall movement, which characterizes a plethora of chronic conditions many of which are refractory to current medical therapies. These insidious clinical disorders primarily affect the arterial wall and blood resulting in loss of organ function [35-59].

Diastolic dysfunction is the ubiquitous precursor to so many chronic conditions that one wonders how scientists have yet to put two-plus-two together. It is an invariant accompaniment to intrinsic cardiac diseases like coronary artery disease and chronic heart failure. It is one of the earliest and most consistent findings in arterial hypertension, seen before myocardial hypertrophy and arterial wall stiffness manifest. Diastolic dysfunction is present in asymptomatic obese individuals. It is present in early diabetes, the globally escalating metabolic syndrome, as well as chronic kidney disease and fatty liver disease all of which take origin in the deterioration of the magnetic and blood-borne energy field. Contemporary medical science isn't even close to finding a cure for any of these conditions.

The field is not limited to the cardiovascular system but, instead, involves a broader nexus of primarily mesodermal elements that compose tissues like blood, muscle, liver, and spleen. The common shared feature among the organs and tissues of the field is an active iron metabolism. The central player in this nexus of relations is the liver which orchestrates the body-wide disposition of iron and which also plays a central role in synthesis and distribution of molecular energy substrates. The spleen and immune cells like macrophages also participate in field activities related to iron metabolism [60-68].

We next examine the second aspect of the conjoined energy field, the radiant (light-based) field centered in the interstitial fluid compartment interposing the terminal branches of the arterial system and post-capillary venules, composed of oscillational currents secondary to ambient light-fall on the skin or through conversion of blood-borne field energy into radiant form. This second field is organized by the kidneys and its functions include diverse aspects like vitamin $\mathrm{D}$ metabolism, the flow of electrical currents through the nervous system and, at the cellular level, participation in protein folding and unfolding dynamics. 


\section{Radiant Energy \& Interstitial Water}

By the early 1920s it was known that sunlight, ultraviolet (UV) light and cod liver oil were effective in preventing and reversing rickets, a metabolic bone disease, the incidence of which had skyrocketed in previous decades among individuals inhabiting industrialized urban areas in upper northern latitudes. Vitamin D was isolated from the skin of lab animals in 1922 and it soon became apparent that it was the common thread that mediated the actions of these three modalities. Vitamin D is a proxy for sunlight in the body $[69,70]$.

In the 1980s a stream of reports began to surface documenting deficient vitamin $\mathrm{D}$ levels in various infectious and autoimmune disease like tuberculosis, multiple sclerosis, type I diabetes, inflammatory bowel disease rheumatoid arthritis, psoriasis and more [71]. What does insufficient vitamin $\mathrm{D}$ in the body have to do with an increased tendency toward inflammation? And how does this relate to sunlight exposure? Recent reports highlight this relationship.

A Norwegian study found that individuals with psoriasis had significant clinical improvement in skin lesions after 16 days of sub-tropical sun exposure which was preceded by changes in immune function. Pro-inflammatory cytokine and $\mathrm{T}$-cell levels in both skin and blood decreased and were replaced by 'tolerant' anti-inflammatory T-cell progeny [72]. A Scottish study using narrowband UV phototherapy in subjects with various immune-mediated skin disorders found similar shifts in immune function along with increased vitamin D levels after 4 weeks of treatment [73]. How can such effects be understood on any basis other than an energy transfer?

As we will see in the third part of the paper, inflammation occurs as a result of insufficient radiant energy currents in the interstitial fluid and vascular compartments and signals a shift to dielectric molecular-driven energy generation at the cellular level. Both infectious and autoimmune disorders are primary energy deficiency states, plain and simple. The evidence is compelling.

It is well established that autoimmune disorders and infectious diseases tend to cluster in seasonal and geographic patterns related to the quantity and quality of ambient sunlight reaching the earth's surface. At the $45^{\text {th }}$ parallels, for example, available light energy gradually decreases from about 12 hours per day near the autumnal and vernal equinoxes to about 9 hours at the winter solstice. During this period the quality of light is markedly attenuated due to the incident angle of solar rays.

The energy deficiency syndromes tend to express themselves more commonly at high latitudes or in winter and spring months after sustained periods of light deprivation. Hippocrates was the first to describe such temporal variations. Chronobiological patterns have been reported in autoimmune disorders, multiple sclerosis being the most thoroughly documented, and infectious diseases like tuberculosis [74-78]. Since the turn of the $20^{\text {th }}$ century there have been five pandemics including the recent Covid-19 outbreak all of which have shown similar circannual patterns [79]. Neoplastic conditions like breast cancer also exhibit seasonal behaviors that appear to influence survival patterns [80-82].

Since its discovery in the 1920s many studies affirm that blood vitamin D levels correlate with ambient light exposure and serve as a reliable proxy by which to gauge its effects. Many reports, too numerous to cite, chronicle the relationship between deficient vitamin $\mathrm{D}$ levels and various autoimmune disorders [83-112]. At the $45^{\text {th }}$ parallels there is a null period between November and February during which UV rays are insufficient to trigger vitamin D synthesis. Such fluctuations roughly correlate with seasonal variations in disease incidence and activity [113-118].

A host of factors including ethnicity and cultural factors like mode of dress play into the picture. Dark-skinned peoples require up to a 6 -fold greater UV exposure to get the same blood levels of vitamin D as light-skinned people. In the northern US dark-skinned people are predisposed year-round to vitamin $\mathrm{D}$ deficiency but especially in winter [119-123]. This must certainly play a role in the higher morbidity and mortality rates seen in this group during the Covid-19 pandemic. Anything that affects transmission of light energy affects vitamin D synthesis, the so-called sunshine hormone. The mechanisms behind this energy transformation in the body have remained elusive until recently.

The most remarkable and far-reaching conceptual transformation to emerge in experimental science in recent decades has been the rediscovery of elemental water. The recognition of dozens of anomalous properties of water not explainable on the basis of its chemical properties calls into question the atomistic chemical hypothesis. The most significant contributions have come from biologist Gerald Pollack whose work, The Fourth Phase of Water, is already a classic [124].

Most significantamong the so-called anomalous behaviors of water is its ability to undergo phase transitions between three distinct states - ice, liquid, and vapor - each directly reflecting its energy content. Many weather and seasonal changes are mediated by transitions in water state. As Pollack observes, 'what moves water moves the world.' The same can be said for the role of water in the body in terms of mediating between states of health and illness.

A serendipitous encounter in the late 1990s with a 
researcher studying blood vessel flow patterns piqued Pollack's curiosity. To experimentally model such flow the scientist had suspended tiny microspheres in water and pumped them through tunnels drilled in transparent gel material. To his surprise he repeatedly observed a clear peripheral zone devoid of microspheres immediately adjacent to the gel surface which extended for a variable distance toward the center of the water column. How to explain such spontaneous ordering?

Pollack researched the literature and found that the phenomenon had been described as early as 1949 . Repeating the studies his team confirmed the finding and launched an intensive series of experiments to determine its nature. Results supported that some process in the water near the gel surface seemed to repel solute particles into the adjacent more central region of the water column. They called the clear peripheral region the 'exclusion zone' (EZ) and the interior portion of the column 'bulk water.'

Once formed the EZ remained stable for hours. Its thickness often extended $\sim .1-.5 \mathrm{~mm}$ from the gel surface imputing that the zone was composed hundreds of thousands of layers of water molecules, equivalent to a lineup of marbles extending over several dozen football fields. This indicated to Pollack the presence of longrange ordering forces.

Using microelectrodes Pollack's team found significant differences between EZ and bulk water: EZ was negativelycharged, more alkaline, dense and viscous; bulk water was positively-charged, acidic, with $\mathrm{pH}$ often as low as 1-2 suggesting accumulation of protons. As the two phases of water formed a charge separation took place. The presence of current flow between the two suggested that water functions in vivo as a battery. As we will see, these two opposing water phases represent primary aether effects mediated by the magnetic and dielectric fields.

Pollack's team found that the EZ tended to form along hydrophilic surfaces and required a molecular template. They deduced that as the EZ acquired spatial order (and physical force) it pushed solute particles into the adjacent bulk water the way glaciers push out rocks. Studies by physical scientists suggest that EZ water has a quasicrystalline structure and arranges itself in stacked honeycomb sheets, hence the term structured water. Pollack regards it as a distinct fourth phase beyond the traditional solid, liquid and vapor states. As the battery metaphor implies, structured water appears to hold and deliver energy when needed. It seems likely that the fourth phase of water is a resonant energy state.

In recent decades there has been an explosion of research in the physical sciences using $x$-ray scattering, NMR spectroscopy, and $\mathrm{x}$-ray crystallography to study protein structure and folding dynamics [125-129]. All the various methods substantiate the key role played by water in protein-related dynamics. To be biologically active proteins must acquire a so-called hydration shell consisting of multiple layers of water molecules sometimes extending up to $25 \AA$ from the protein surface. The hydration shell appears to be instrumental in determining not only 3-D protein structure but the folding process itself. Beginning in the 1950s research scientist Gilbert Ling emphasized the primary role of water in all cell functions. In his 2001 monograph Life at the Cell and Below-Cell Level, Ling argues that the charged surfaces in the intracellular compartment produce ordering in nearby water molecules [130].

The hydration shell, which surrounds hydrophilic domains of most intracellular proteins and membranes, spontaneously organizes into a complex hexagonal lattice-type arrangement, which researchers have compared to a semi-crystalline state. The protein-water complex becomes structurated and assumes gel-like consistency. Hydration shell water surrounding proteins has physical properties distinct from that of bulk water in the adjacent fluid spaces including net negative charge, higher $\mathrm{pH}$ and increased density. As Pollack comments, 'cell water is EZ water.' Changes in water state, both in the intracellular and extracellular fluid compartments, would seem to provide an ideal energy source for many proteinmediated biological processes.

It is now widely accepted that all physiological functions in biological organisms are affected by the folding and unfolding of proteins which, as with the heart, represent states of polarization and depolarization. While genes direct the synthesis of proteins, folding and unfolding is orchestrated in the cytoplasm by the flow of energy currents. Disposition of surrounding water plays a critical role in the transition between various energetic states of normally folded proteins not to mention the failure of proper protein folding [131-135].

Pollack's team asked another key question: what keeps the EZ charged and functioning, i.e., in a resonance state? What is its energy source? One evening Pollack's research fellow left without cleaning his work desk and upon returning in the morning observed that the EZ in the water sample on the microscope stage had diminished to half its former size. Within several minutes in front of his eyes the EZ returned to its previous width, as though the light from the microscope had provided fuel. In short order it became apparent that water is sensitive to radiant energy.

Subsequent experiments revealed that water is sensitive not just to the visible part of the spectrum but the infrared and ultraviolet ranges as well. Radiant electromagnetic energy promotes EZ growth. As in photosynthesis, light supplies energy for building order and producing charge 
separation (or resonance). In subsequent experiments the degree of EZ growth was frequency-related with the ultraviolet end of the spectrum least, visible light more, and infrared frequencies most effective.

The most obvious example of such biologically induced light effects is the use of phototherapy in neonatal jaundice. Direct exposure of light on the skin of affected babies causes insoluble bilirubin molecules in the interstitial fluid compartment to undergo rapid photoisomerization reactions to form nontoxic, excretable water-soluble isomers. It is likely that light-induced charge separation related to EZ growth provides the energy equivalents to drive such reactions [136]. And, equally, it is on this basis that the effects of vitamin D can be understood.

In 1969 researchers discovered the vitamin D receptor which mediates the effects of vitamin $\mathrm{D}$ at the cellular level. Over the ensuing decades vitamin $\mathrm{D}$ receptors were found in over 30 tissues throughout the body including kidneys, skin, bone, cartilage, intestines, pancreatic $\beta$-cells, prostate, breast, muscle and adipose tissue, multiple cell lines of the immune system not to mention a host of various cancer types. Activated vitamin D influences at least 500 different gene activities through receptor-mediated epigenetic mechanisms [137].

Given such biological potency one would expect vitamin D to be a panacea for every conceivable form of inflammation but such is not the case. For every study showing benefits with vitamin $\mathrm{D}$ supplementation another finds no results [138-140]. Why are effects so mixed? It would appear that the rate-limiting step lies not in synthesis of the vitamin $\mathrm{D}$ precursor but in its conversion to the biologically potent analog.

Through photosynthesis-like mechanisms, UV rays in the skin induce formation of vitamin $\mathrm{D}$ which, subsequently, is transformed to its intermediary $25(\mathrm{OH}) \mathrm{D}_{3}$ and, finally, to the highly-active $1,25(\mathrm{OH})_{2} \mathrm{D}_{3}$ form, which is said to be 500-fold more biologically active. These latter two energy-requiring steps are affected by the ubiquitous superfamily of enzymes known as the cytochrome p450 system. These protein structures, which function on the basis of EZ water dynamics, are activated by externally applied light pulses [141-144]. Skin keratinocytes, one of the few cell lines other than kidney cells capable of completing the entire chain of vitamin $D$ synthesis, contain $\beta$-1-hydroxylase, which transforms vitamin $\mathrm{D}$ into its highly active form [145-147]. It seems likely that the biological effects of activated vitamin $\mathrm{D}$ are mediated on the basis of internal energy generation via aether dynamics in structured water.

\section{Aether Dynamics \& Nerve Function}

The second locus in which radiant water-based aether dynamics play a key role is the nervous system. Since development of electroencephalography and electrocardiography in the early $20^{\text {th }}$ century scientists have amply documented the flow of electrical currents through both central and peripheral nerve tracts and yet there has been surprisingly little discussion as to where these currents take origin or how they induce their physiologic effects.

Around the turn of the $20^{\text {th }}$ century scientists regarded neurons as tiny batteries that generated their own electrical currents but this explanation doesn't fly in the face of clinical events like sudden cardiac arrest in which there is immediate loss of consciousness and all neuronal function at the moment cardiac activity ceases. How to explain the tight functional linkage between the two compartments?

Given the directionality of flow currents in nerves the question arises as to where peripheral sensory nerves, which course toward the brain and spinal axis, derive their currents. The unavoidable conclusion is that they originate in the interstitial fluid compartment. By the same token, given that the surface of the cerebral hemispheres is lined by dendrites, which convey currents directionally into the deeper brain structures, and which are in direct contact with cerebrospinal fluid, one must draw similar conclusions as to the origin of electrical currents in the brain.

The flow of currents in the nervous system is driven by cardiac dynamics. Each systolic contraction of the heart creates a suctional force in nerves which draws currents forward into both peripheral sensory nerves and dendrites over the outer surface of the brain. When the heart dilates it moves fluids; when its contracts it moves electrical currents. This substantiates the claim of Swedish radiologist Björn Nordenström in his overlooked work Biologically Closed Electric Circuits (1983) that there is not one but two overlapping circulations, one consisting of the flow of fluids and the other of energy currents [148].

A more pressing issue concerns the question of nerve function itself. What do nerves actually do? It has been recognized for two centuries that limb regeneration depends on the presence of intact nerves in the surrounding medium. In the 1820 s T. J. Todd observed that severing or deflecting the sciatic nerve in salamanders inhibited regeneration and healing. He speculated that nerves produce factors necessary for such activities and so the notion that nerves possess a trophic function arose. It is now recognized that tissue regeneration in all vertebrate species requires intact peripheral nerves but mechanisms remain poorly understood [149-155]. 
In the 1920s Swiss biologist Emile Guyénot performed a series of experiments in the crested newt, Tritus cristatus, a species which retains the ability to regenerate lost limbs throughout life. When nerves were deflected from their usual course and re-implanted in the dermis close to the base of a leg a supernumerary hindlimb was generated. When the nerve was positioned at the base of the tail an extra tail developed, or when implanted along the spine a dorsal crest arose [156-157]. Based on such results it was argued that nerves possess a non-specific 'trophic' action the effects of which depended on the area into which they were implanted. One obvious conclusion is that energy currents carried by nerves induced generation of the various structures.

Higher vertebrates including humans possess little capacity to regenerate lost limbs but nerves play an important role in wound healing, which is but a more restricted form of regeneration. Loss of nerve potentials, as in traumatic spinal cord injury, is associated with impaired wound healing in tissues below the injury level. The same problem occurs in long-standing diabetes in which impaired nerve function is a well-recognized accompaniment.

Diabetes is a leading cause of limb amputation in older people. Peripheral neuropathies, diffuse vascular disease, chronic skin ulcers, and defects in bone metabolism all go hand-in-hand in late-stage diabetes. What other than the flow of energy currents distinguishes the capacity to regenerate from the purely deteriorative effects of diabetes? The discovery of the preconditioning phenomenon in recent decades sheds new light on the trophic function of nerves and the significance of organized flow currents in generation and wound healing. In the 1980s Charles Murry and colleagues, seeking to understand mechanisms at play in the development of myocardial infarction, tested whether intermittently reopening the coronary arteries to allow for brief return of blood flow altered the course of cellular injury [158]. In a control group of dogs, a coronary artery was clamped for 40 minutes to assess the extent of infarct damage. Another group underwent a series of four 5-minute arterial occlusions interrupted by 5-minute intervals of reperfusion. Afterward the artery was clamped for 40 minutes. To their complete surprise, animals that received preconditioning (PC) pulses had only about $25 \%$ of damage as the control group.

Subsequent studies revealed that the protective effect lasts for $\sim 2-3$ hours, disappears, and then recurs $\sim 24$ hours later (called the second window of protection) and persists for 24-72 hours. The application of brief periods of ischemia by interruption of blood flow to any organ or limb confers body-wide protection against subsequent ischemia [159162]. The PC phenomenon is now recognized to be the most powerful endogenous form of tissue protection ever discovered. For 35 years researchers have sought answers in the maze of cellular and molecular pathways with little success. To date no satisfying explanation has emerged.

Like regeneration the PC response appears to require intact nerves. A 2010 study, testing the hypothesis that $\mathrm{PC}$ requires both neural and vascular pathways, found that when remote PC was performed in the hind limb of mice its beneficial effects were abolished by occlusion of the femoral vein and sectioning of the sciatic nerve [163]. In a 2008 study renal sympathetic nerves were cut and animals subjected to prolonged renal arterial occlusion. Not surprisingly, the nerve-sectioned animals had more severe ischemic injury [164]. It is well established that the $\mathrm{PC}$ response is blunted or absent in diabetics.

Another issue concerns the role that neurons play in consciousness and, in particular, the generation of internal visual images. In viewing the external world there is the subjective perception that one is looking outwardly through the eyes but such is not the case. In reality a wave front reflects off an image, excites photosensitive retinal cells generating nerve currents that simultaneously activate cortical regions in the occipital lobes where a 3-D representation is created to be viewed in camera by the subject.

There is a well-described clinical phenomenon called cortical blindness, caused by a variety of factors like stroke, tumors or toxins, in which retinal function is preserved but the individual is functionally blind [165167]. What happens in such cases? In order to answer this, we must reconsider the nature of light.

When one gazes up into the nighttime sky and sees a full moon hovering above what is the source of light radiating from its surface? Conventional wisdom has it that light photons from the sun reflect off the lunar surface back toward earth and, subsequently, into the eye of the viewer. But this is pure conjecture. Radiant solar energy undoubtedly reflects off the moon's surface back toward the viewer on earth but this isn't to say that light itself is reflected.

As solar radiation approaches the lunar surface it interacts with the ambient magneto-dielectric field thereby generating light. Properly speaking what one sees is not reflected sunlight but rather moonlight. Light is produced in situ by a resonance mechanism involving the same three aether modalities at play in living bodies. If sunlight really traveled through open space it should light up the solar system like a grand gymnasium but it doesn't. This same interaction accounts for the generation of light in the earth's atmosphere during the daytime. As Wheeler points out, light is not a material emanation, a so-called photon, or even a wave packet but a pure induction (resonance) phenomenon. 
In the case of cortical blindness, which medical scientists explain simply on the basis of the injury mechanism (which isn't really an explanation), the inability to generate internal light-based images must be ascribed to the failure of radiant currents streaming through the nerves to resonate the magneto-dielectric field in the affected neuronal territory.

The striking similarity between Tesla coil emissions, Lichtenberg figures and the architecture of cerebral neurons lends support to this mechanism (Figure 1). In neurons the linear component represents the radiallyoriented dielectric field while the lightning-like angular branching indicates repulsion induced by the surrounding magnetic field. Radiant energy flow in neurons interacts with the conjugate field producing, through resonance, aether torque which induces light emission internally generating the visual field. This supports the luminiferous 'light-bearing' aether concept although by a qualitatively different mechanism than postulated by $19^{\text {th }}$-century scientists.

So, it would seem that nerve function, as suggested by regeneration of severed limbs in lower vertebrates, wound healing, the preconditioning phenomenon, and generation of internal visual images, occurs purely on the basis of energy transfer via the aether field thereby engendering a diverse range of physiological effects.

Figure 1. Striking similarities in configurations of Tesla coil emissions, Lichtenberg figures and cerebral neurons explained on the basis of dielectric and magnetic interactions.

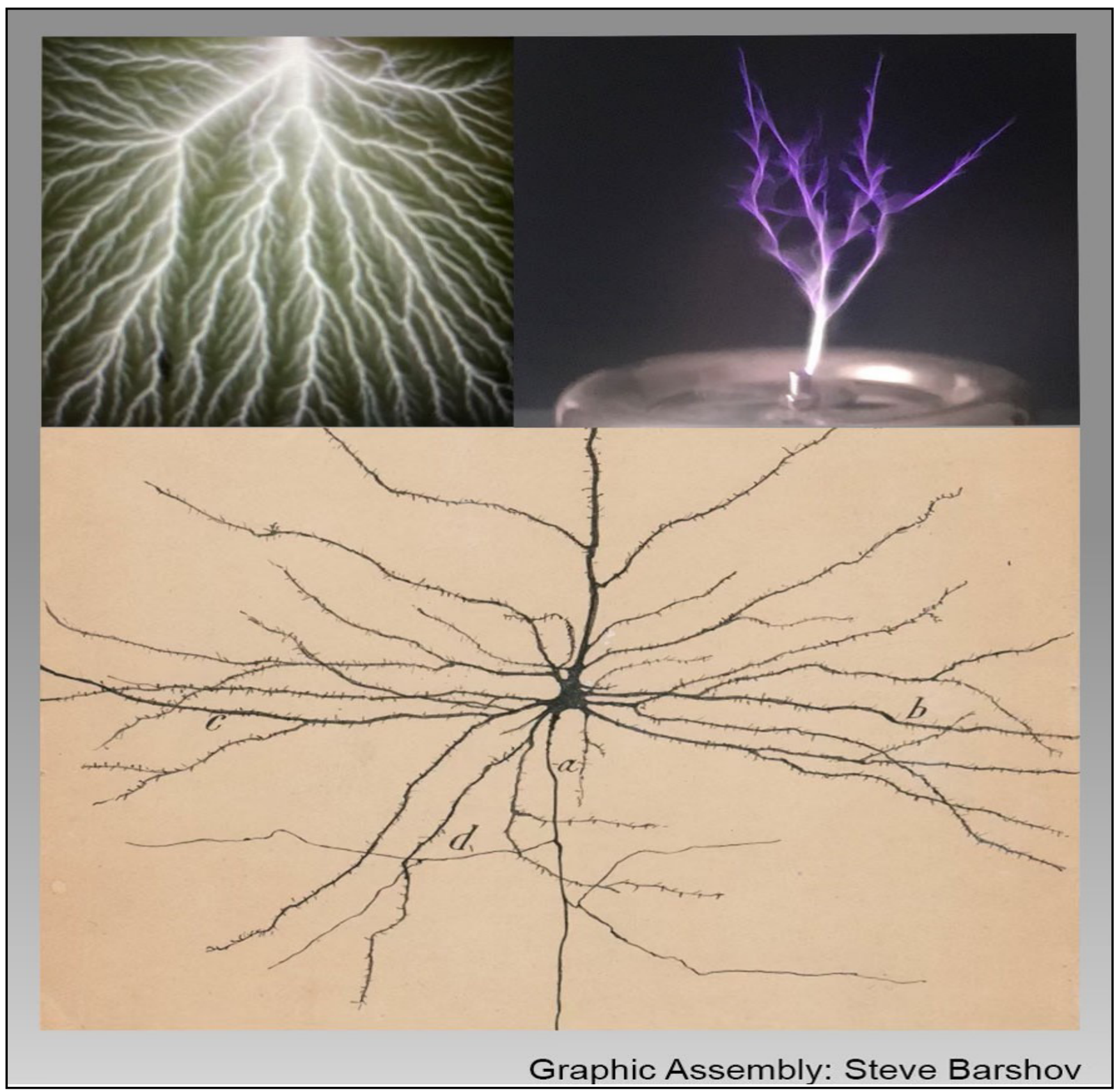




\section{Aether and the Dielectric Field}

The most difficult concept surrounding the aether modalities concerns the dielectric field, in part because, like aether, it has been defined in a negative sense based largely on what it isn't rather than what it actually is. Add to this misleading and contradictory concept surrounding dielectricity and it is not at all surprising that it continues to baffle many.

Dielectricity, as determined by its relationship to externally applied electricity, is said to be somewhere in the spectrum between an electrical conductor and an insulator. When an electric potential is applied to the surface of a dielectric object, currents do not flow as in the case of a conductor. On the other hand, electrical currents are not repelled as with an electric insulator. If it is neither conducting nor repelling electric currents then what is it doing?

Instead of conducting electric currents, dielectric materials undergo internal polarization, i.e., separation of positive and negative charges, which amounts to creation of an internal electric field. Dielectric materials are thus said to possess high polarizability expressed numerically as the so-called dielectric constant, which is supposedly an indication of energy storing capacity (capacitance). Like the problem raised by the hypothetical elastic recoil of the heart following systolic contraction, in which energy appears to come out of nowhere and cause dilation of the ventricle, the issue of energy storage and capacitance in dielectric objects would seem to demand a direct relation between the dielectric and aether fields.

In living bodies dielectric forces originate in the interstitial fluid compartment and are mediated by water, which has one of the highest dielectric constants, i.e., polarizability, of all substances indicating its ability to 'store' energy which amounts to de novo energy generation through the conjoined magneto-dielectric field and aether. Paradoxically, in addition to its pronounced dielectric properties, another anomalous property of water is its ability to conduct electric currents which puts it in a unique class of its own.

Through the aegis of water, the effects of the dielectric field manifest in tissue architecture and at the cellular layer through induction of gene expression and formation of structural elements including molecular energy substrates like ATP. In Biologically Closed Electric Circuits, Björn Nordenström provides a detailed overview of the actions of the dielectric field [168].

Figure 2. Nordenstrom's electro-osmosis experiment resulting in differential water levels between the cathodic and anodic poles in a $\mathrm{U}$-shaped glass tube packed with cotton wool.

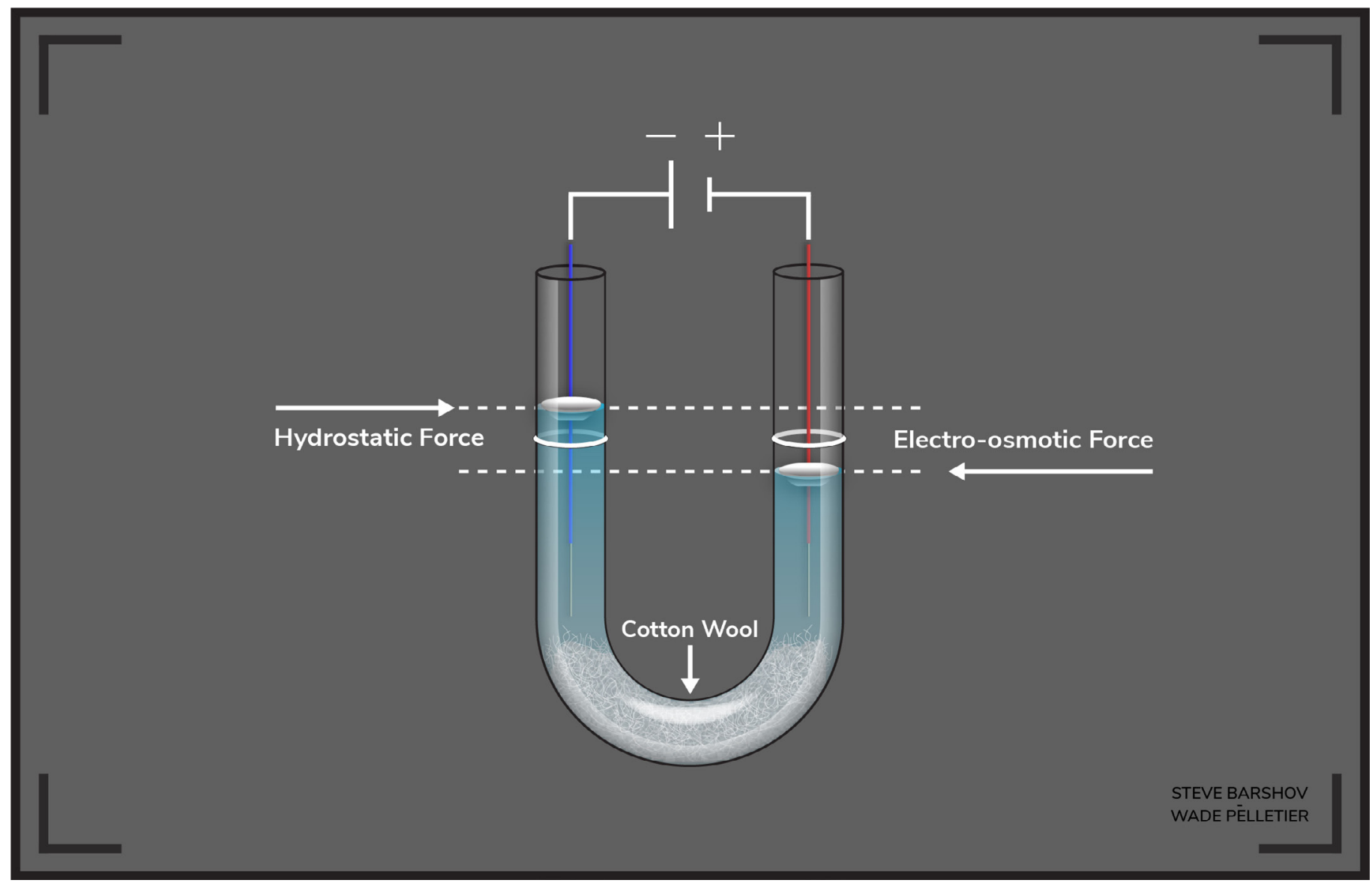


In one experiment intended to demonstrate the effects of electric fields in water Nordenström packed a U-shaped glass tube with cotton wool in its lower curved portion to simulate capillary resistance (Figure 2). Both limbs of the tube were filled with water and metallic electrodes connected to a DC power source were placed on each side. After a variable period of time, and depending on the strength of the battery, one observes differential water levels in the two limbs of the tube with the left (cathodic) side higher than the right (anodic) pole. What is happening here?

Differential accumulation of ion species at the two poles which is said to be a result of electro-osmosis, the electrically-induced migration of charged particles. With water, we see accumulation of negatively-charged hydroxyl ions $\left(\mathrm{OH}^{-}\right)$around cathode and positively charged hydronium ions $\left(\mathrm{H}_{3} \mathrm{O}^{+}\right)$at the anode, a result of water's dielectric polarizability. But polarization does not explain the differential water layers between the two poles.

Another factor is the so-called electrolytic decomposition of water in which electric currents induce transformation of water with release of hydrogen into the atmosphere at the cathodic pole and release of oxygen at the anode. The net loss of hydrogen at the cathode results in a surplus of $\mathrm{OH}^{-}$ions around the cathode while the loss of oxygen at the anode leaves an excess of protons $\left(\mathrm{H}^{+}\right)$which combine with nearby water to form $\mathrm{H}_{3} \mathrm{O}^{+}$. But again, we are hardpressed to explain the differential water levels on the basis of this covalent reorganization of molecular water into gas products. How then can it be explained?

The spatial reorganization of water is not a result of migration of ion species or molecular reactions but, instead, a field-mediated effect. Real forces produce the differential fluid levels as well as electro-osmosis. Electrical currents streaming through the electrode (a conductor) at the cathode generate a magnetic field around the wire which causes expansion of water. By the same token, currents drawn out by the anode induce dielectric contraction in surrounding water which causes its level in the tube to drop. When one says that water is polarizable, it means that electricity causes the dielectric and magnetic fields to repel each other as in magnetic induction. This same effect can be observed at a planetary level in the periodic waxing and waning of the tides.

Since the time of Newton scientists have explained tidal fluctuations on the basis of gravity but as more evidence surfaces this hypothesis seems baseless. From antiquity it was observed that the tides swell when the moon is directly overhead and thus its connection with these events seems inescapable. To impute the tides to a lunar gravitational effect on water at first seemed reasonable but with the discovery that high tides occur at the same time $180^{\circ}$ on the opposite side of the globe this idea was out on a limb [169].
Not only do we confront the sheer improbability of the lunar gravitational effect, which is a small fraction of the strength of earth's gravity field, operating at a quartermillion miles away, but add to that the diameter of the earth, another 8,000 miles, and the fact that it must overcome the earth's own gravitational field on the opposite side of the globe and we begin to see the flawed chain of logic that props up this contemporary scientific fable.

The nail-in-the-coffin for the lunar gravity hypothesis comes with recognition that at the same time high tides happen on the global surface at $\mathrm{O}^{\circ}$ and $180^{\circ}$, low tides occur at $90^{\circ}$ and $270^{\circ}$. Given that tides are not (and cannot) be produced by the bulk movement of water we must suppose the presence of two opposing forces, namely the magnetic and dielectric. The fact that the orbit of the moon lies near the earth's equator where the dielectric plane of the earth's conjoined field resides, it seems likely that tidal movements are created by phasic interactions between the earth's magnetic and dielectric fields induced by the passage of the moon overhead. Synchronous tide-related fluctuations are also found in the rhythmic swelling and contraction of tree diameters which can only be explained on the basis of such dynamics [170-174].

It is thus apparent that the dielectric properties of water, i.e., its tendency to undergo polarization, are mediated by interactions between the dielectric and magnetic fields and that its so-called capacitance, the ability to store energy, can only be explained on the basis of an aetherrelated resonance effect.

Returning to Nordenström's biologically closed electric circuit in which DC currents from a primary energy source interact in water to generate opposing field effects, we observe such a dynamic at play in morphogenesis. It is hardly surprising that the heart, the center of the body's energy-generating system, is the first organ to assume its functions. Nordenström likens the arteries and veins to electric cables that connect the heart to all the cells and tissues of the body.

This analogy is reinforced by the polar relationship of the three body cavities: the chest, containing the lungs and heart, supplies energy to the blood and interstitial fluid compartment; the expansile abdominal cavity, in which the liver functions as the cathodic pole, supports the functions of the magnetic field; the head, with its dominance of contractile dielectric forces secondary to nerves pulling energy currents form the blood and interstitial water compartment, represents the anodic pole in the body's closed electric circuit. (Figure 3)

In the 1930s Yale anatomist Harold Saxton Burr exposed developing embryos of various species to DC currents and observed reproducible electrical gradients between 
the head and tail regions in various embryo species. The head region was electro-negative (anodic) with respect to the tail with voltage differences in the $100-700 \mu \mathrm{v}$ range. Voltage potentials between various regions changed from moment to moment which, Burr suggested, was related to cellular activities like mitosis, differentiation, and metabolism [175-180]. Given that electrical currents are associated with fields, Burr concluded, it is likely that living organisms possess not many small fields but a single large field.

Developmental fields manifest as organized electrical gradients, i.e., voltage potentials, both intracellularly and in the interstitial fluid space, with spatial and temporal

Figure 3. Biologically closed electric circuit between heart (energy source), liver (cathode), and brain (anode) mediating polarized dielectric currents.

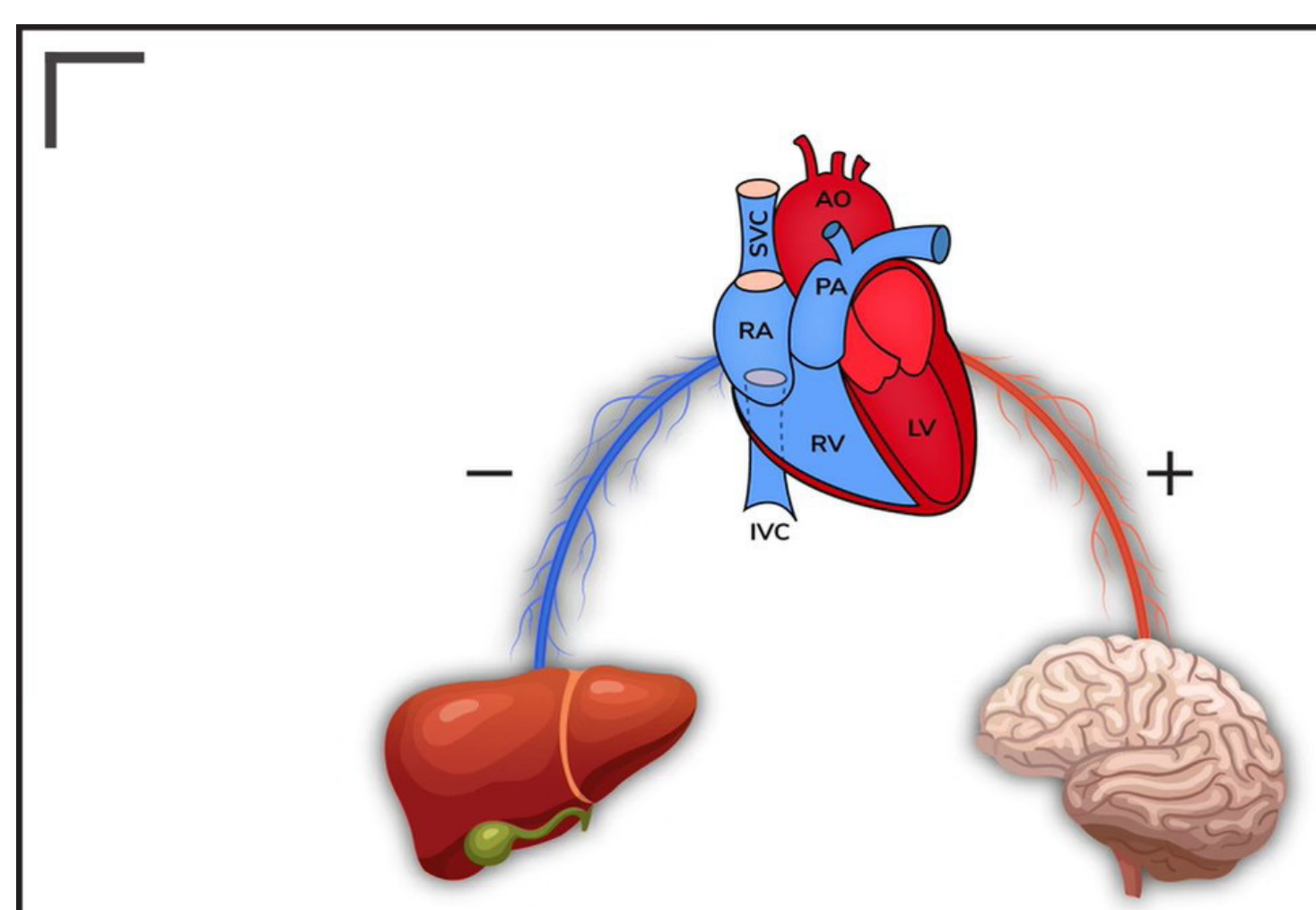

In a 2005 review of biological fields researcher Colin McCaig details experiments supporting the presence of a developmental field and the role played by DC currents [181]. When amphibian embryos were exposed to an externally applied DC current field internal gradients were altered and developmental defects more common. In embryos without electrical field exposure only $17 \%$ developed anomalies. In embryos placed randomly in the field $62 \%$ developed defects. When the cathode was placed at the tail $93 \%$ of embryos were abnormal. When the long axis of the animal was perpendicular to the field $75 \%$ were malformed. Observed defects were profound and included absent or misshapen heads, absence of
STEVE BARSHOV WADE PÉLLETIER

attributes. In order for a current to flow there must be differential resistance, i.e., charge separation, between adjacent fluids and tissues. Such current flow is made possible only by an internal field, i.e., the dielectric, that mediates, through polarization, the organization and differentiation of cells into tissues and organs.

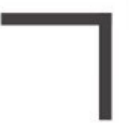

one or both eyes, abnormal development of upper limbs and incomplete closure of the neural plate. Such events, says McCaig, suggest that internal field gradients were 'scrambled' by externally applied DC currents.

More recent studies indicate that such fields are necessary for limb regeneration and wound healing. Biologist Michael Levin, a leading proponent of developmental fields, published linchpin studies confirming that appendage regeneration requires alterations in ion currents and membrane gradients, i.e., the dielectric field $[182,183]$. He offers compelling evidence linking changes in membrane potentials to changes in gene expression. 
Evidence from developmental biology thus points to the presence of a complex, organized field structure that generates voltage gradients, currents, and resistances that actively mediate the structural organization of living bodies via the conjoined magneto-dielectric and aether fields.

\section{Aether Affirmed}

Evidence we have presented affirms the presence of complex aether-mediated dynamics driven by the conjoined magneto-dielectric field and the flow of electric currents in the energy economy of living bodies. In the third part of our paper, we examine how alterations in energy generation pathways in the various compartments manifest in a host of clinical disorders some of which are wholly unexplainable on the basis of cellular and molecular mechanisms. The recognition of such disturbed dynamics in the pathogenesis of various disease conditions will point the way to new (and necessary) therapeutic possibilities.

\section{References}

1. Is Water $\mathrm{H}_{2} \mathrm{O}$ ? Evidence, Realism and Pluralism. Hasok Chang. publ. Springer 2012

2. Anatomical Studies on the Motion of the Heart and Blood (1628). William Harvey Leake translation; Charles Thomas Publisher, Springfield Illinois, 1958

3. Galen's System of Physiology and Medicine Rudolph E. Siegel publ. S. Karger, Basel, Switzerland, 1968; pp. 30-47

4. Negative intraventricular diastolic pressure in patients with mitral stenosis: evidence of left ventricular diastolic suction. Sabbah HN, Anbe DT, Stein PD Am J Cardiol 1980; 45(3):pp 562-66.

5. Left ventricular diastolic suction as a mechanism of ventricular filling. Hori M, Yellin EL, Sonnenblick EH Jpn Circ J 46(1): pp 124-129; 1982

6. The heart as a suction pump. Robinson TF, Factor SM, Sonnenblick EH Scientific American 254(6): pp 84-91; 1986

7. Diastolic Dysfunction. Little WC, Cheng CP Cardiol Rev 6(4): pp 231-239; 1988

8. State of the art: 'diastology' research 1998. Oki T J Med Invest 45(1-4): pp 9-25; 1998
9. The heart is not a pump: a refutation of the pressure propulsion premise of heart function. Marinelli R, Fürst B, van der Zee H, McGinn H, Marinelli W Frontier Perspectives 5(1): pp 15-24; Fall-Winter 1995

10. Spiral laminar flow in arteries? Stonebridge PA, Brophy CM Lancet 338(8779): pp 1360-61; 1991

11. Spiral laminar flow in vivo. Stonebridge PA, Hoskins PR, Allan PL, Belck JF Clin Sci (Lond) 91(1): pp 17-21; 1996

12. Helical and retrograde secondary flow patterns in the aortic arch studied by three-directional magnetic resonance velocity mapping. Kilner PJ, Yang GZ, Mohiaddin RH, Firmin DN, Longmore DB Circulation 88(5): pp 2235-47; 1993

13. Physiological significance of helical flow in the arterial system and its potential clinical applications. Liu X, Sun A, Fan Y, Deng X Ann Biomed Engineer 43(1): pp 3-15; 2015

14. Three-dimensional blood flow dynamics: spiral/ helical laminar flow. Stonebridge PA Methodist Debakey Cardiovasc J 2011; 7(1): 21-26

15. Spiral laminar flow: a survey of a three-dimensional arterial flow pattern in a group of volunteers. Stonebridge PA, Suttie SA, Ross R, Dick J Eur J Vasc Endovasc Surg 2016; 52(5): 674-80

16. Patterns of flow in the left coronary artery. Sabbah HN, Walburn FJ, Stein PD J Biomech Engin 1984; 106(3): 272-79

17. Flow visualization study of spiral flow in the aorta-renal bifurcation. Fulker D, Javadzadegan A, Li Z, Barber T Comput Meth Biomech Biomed Engin 2017; 20(13): 1438-41

18. The mechanics of spiral flow: enhanced washout and transport. Huang Zhang P, Tkatch C, Newman R, Grimme W et al. Artif Organs 2019; 43(12): 1144-53

19. Parallel and spiral flow patterns of vertebral artery contributions to the basilar artery. Smith AS, Belton JR Am J Neuroradiol 1995; 16(8): 272-79

20. Flow patterns in the human carotid artery bifur- 
cation. Motomiya M, Karino T Stroke 1984; 15(1): 50-56

21. Spiral systolic blood flow in the ascending aorta and aortic arch analyzed by echodynamography. Tanaka M, Sakamoto T, Sugawara S, Nakajima H et al. J Cardiol 2010; 56(1): 97-110

22. Flow patterns in dog aortic arch under a steady flow condition simulating mid-systole. Endo S, Sohara Y, Karino T Heart Vessels 1996; 11(4): 180-91

23. Blood flow analysis of the aortic arch using computational fluid dynamics. Numata S, Itatani K, Kanda K, Doi K et al Eur J Cardiothorac Surg 2016; 49(6): 1578-85

24. Twist mechanics of the left ventricle: principles and application. Sengupta PP, Tajik AJ, Chandrasekaran K, Khanderia BK JACC Cardiovasc Imaging 2008; 1(3): 366-76

25. 25. Twist and untwist mechanics of the left ventricle. Sengupta PP, Khandheria BK, Narula J. Heart Fail Clin. 2008 Jul;4(3):315-24.

26. Left ventricular twist dynamics: principles and applications. Beladan CC, Câlin A, Rosca M, Ginghina C, Popescu BA Heart 2014 May;100(9):731-40

27. Evaluation of left ventricular torsion by cardiovascular magnetic resonance. Young AA, Cowan BR J Cardiovasc Magn Res 2012; 14(1): 49

28. Evaluation of left ventricular function using left ventricular twist and torsion parameters. Takeuchi M, Otsuji Y, Lang RM Curr Cardiol Rep 2009; 11(3): $225-30$

29. Twist mechanics of the left ventricle. Badano LP, Muraru D Cardiovasc Imaging 2019; 12(4):e009085

30. Left ventricular rotation and twist: why should we learn? Nakatani S J Cardiovasc Ultrasound 2011; 19(1):1-6

31. Transmural left ventricular mechanics underlying torsional recoil during relaxation. Ashikaga $\mathrm{H}$, Criscione JC, Omens JH et al. Am J Physiol Heart Circ Physiol 2004 Feb;286(2):H640-7

32. Left ventricular twist mechanics in the context of normal physiology and cardiovascular disease: a review of studies using speckle tracking echocardiography. Stöhr EJ, Shave RE, Baggish AL, Weiner RB Am J Physiol Heart Circ Physiol. 2016 Sep 1;311(3):H633-44.

33. Spatial orientation of the ventricular muscle band: physiologic contribution and surgical implications. Torrent-Guasp F, Ballester M, Buckberg GD, et al. J Thorac Cardiovasc Surg 2001;122:389 -92.

34. Left ventricular muscle band (VMB): thoughts on its physiologic and clinical implications. Boineau JP Eur J Cardiothorac Surg 2006; 29(Suppl 1): S5660

35. Pathophysiology of diastolic dysfunction in chronic heart failure. Segers VM, De Keulenaer GW Future Cardiol 2013; 9(5): 711-20

36. Evolving focus on diastolic dysfunction in patients with coronary artery disease. Ohara T, Little WC Curr Opin Cardiol 2010; 25(6): 613-21

37. Diastolic dysfunction in arterial hypertension. De Simone G, Palmieri V J Clin Hypertens (Greenwich) $2001 ; 3(1): 22-27$

38. Diastolic dysfunction precedes myocardial hypertrophy in the development of hypertension. Aeschbacher BC, Hutter D, Fuhrer J et al. Hypertens 2001; 14(2): 106-13

39. Left ventricular diastolic dysfunction in newly diagnosed untreated hypertensive patients. Fici F, Ural D, Tayfun S, Kozdag G et al. Blood Press 2012; 21(6): 331-37

40. Relation of arterial stiffness to diastolic dysfunction in hypertensive heart disease. Mottram PM, Haluska BA, Leano R et al. Heart 2005; 91(12): 1551-56

41. Diastolic dysfunction and hypertension. Nadruz W, Shah AM, Solomon SD Med Clin North Am 2017; 101(1): 7-17

42. Effects of obesity on cardiovascular hemodynamics, cardiac morphology, and ventricular function. Alpert MA, Omran J, Bostick BP Curr Obes Rep 2016; 5(4): 424-34

43. Obesity and metabolic features associated with 
long-term development of diatolic dysfunction in an initially healthy population-based cohort. Chau K, Girard N, Magnusson M, Lamiral Z et al. Clin Res Cardiol 2018; 107(10): 887-896

44. Left ventricular diastolic dysfunction in morbidly obese patients in the preoperative for bariatric surgery. Tavares IS, Sousa AC, Menezes Filho RS et al. Arq Bras Cardiol 2012; 98(4): 300-06

45. Pre-clinical diastolic dysfunction. Wan SH, Vogel MW, Chen HH J Am Coll Cardiol 2014; 63(5): 40716

46. Multimarker assessment of diastolic dysfunction in metabolic syndrome patients. Mocan M, Anton F, Suciu S, Rahaian R et al. Metab Syndr Relat Disord 2017; 15(10): 507-514

47. Metabolic syndrome and cardiovascular diseases in Korea. Suh S, Lee MK. J Atheroscler Thromb 2014; 21(Suppl 1): S31-35

48. The metabolic syndrome in early pregnancy and risk of gestational diabetes mellitus. Chatzi L, Plana E, Pappas A, Alegkakis D et al. Diabetes Metab 2009; 35(6): 490-94

49. Metabolic syndrome is associated with electrical and mechanical dysfunction. Yilmaz H, Özcan KS, Sayar N, Kemaloglu T et al. Med Princ Pract 2015; 24(2): 147-52

50. Left ventricular dysfunction in diabetes mellitus: an update. Freire CM, Moura AL, Barbosa Mde M, Machado LJ et al. Arq Bras Endocrinol Metab 2007; 51(2): 168-75

51. Diastolic dysfunction in asymptomatic hemodialysis patients in the light of current echocardiographic guidelines. Malik J, Kudlicka J, Valerianova A et al. J Cardiovasc Imaging 2019; 35(2): 313-17

52. Left ventricular diastolic dysfunction in early-stage chronic kidney disease. Otsuka T, Suzuki M, Yoshikawa H, Sugi K J Cardiol 2009; 54(2): 199204

53. Left ventricular diastolic dysfunction by tissue Doppler echocardiography in pediatric chronic kidney disease. Lindblad YT, Axelsson J, Balzano R, Vavilis G et al. Pediat Nephrol 2013; 28(10): 200313
54. Left ventricular diastolic dysfunction in normotensive postmenopausal women with type 2 diabetes mellitus. Maiello M, Zito A, Cecere A et al Cardiol J 2017; 241): 51-56

55. Left ventricular diastolic dysfuction in diabetic patients: pathophysiology and therapeutic implications. Tsujino T, Kawasaki D, Masuyama T Am J Cardiovasc Drugs 2006; 6(4): 219-30

56. Association between non-alcoholic fatty liver disease and left ventricular diastolic dysfunction in patients of type 2 diabetes. Saluja M, Kumar K, Swami YK, Meena SR J Assoc Physicians India 2019; 67(8):20-24

57. Nonalcoholic fatty liver disease and advanced fibrosis are associated with left ventricular diastolic dysfunction. Chung GE, Lee J-H, Lee H, Kim MK et al. Atherosclerosis 2018 May;272:137-144.

58. Non-alcoholic fatty liver disease is associated with left ventricular diastolic dysfunction in essential hypertension. Fallo F, Dalla Pozza A, Sonino N Lupia M et al. Nutr Metab Cardiovasc Dis 2009 Nov;19(9):646-53

59. Association between diastolic cardiac dysfunction and nonalcoholic fatty liver disease: A systematic review and meta-analysis. Wijarnpreecha $\mathrm{K}$, Lou S, Panjawatanan P et al. Dig Liver Dis 2018 Nov;50(11):1166-1175.

60. Iron and the heart: A paradigm shift from systemic to cardiomyocyte abnormalities. Patarek A, Mackiewicz U, Macczewski M J Cell Physiol 2019; 234(12): 21613-21629

61. Keeping heart homeostasis in check through the balance of iron metabolism. Vela D Acta Physiol (Oxf) 2020; 228(1):e13324

62. The molecular mechanisms of iron metabolism and its role in cardiac dysfunction and cardioprotection. Ravingerová T, Kindernay L, Barteková M et al. Int J Mol Sci 2020; 21(21): 7889

63. Current understanding of iron homeostasis. Anderson JG, Frazer DM Am J Clin Nutr 2017; 106(Suppl 6): 1559S-1566S

64. The liver: conductor of systemic iron balance. Meynard D, Babitt JL, Lin HY Blood 2014; 123(2): 168-76 
65. A general map of iron metabolism and tissue-specific subnetworks. Hower V, Mendes P, Torti FM et al. Biosyst 2009; 5(5): 422-43

66. Iron biology in immune function, muscle metabolism and neuronal functioning. Beard JL $J$ Nutr 2001; 131(2S-2): 568S-579S

67. The spleen in local and systemic regulation of $i m-$ munity. Bronte V, Pittet MJ Immunity 2013; 39(5): 806-18

68. The Iron Curtain: Macrophages at the Interface of Systemic and Microenvironmental Iron Metabolism and Immune Response in Cancer. DeRosa A, Leftin A Front Immunol. 2021 Apr 27;12:614294.

69. The Discovery of Vitamin D: The Contribution of Adolf Windaus. Wolf G J Nutr 2004; 134: 12991302

70. A short history of phototherapy, vitamin $\mathrm{D}$ and skin disease. Jarrett P, Scragg R Photochem Photobiol Sci 2017; 16(3): 283-290]

71. Vitamin D and the immune system: new perspectives on an old theme. Hewison $\mathrm{M}$ Endocrinol $\mathrm{Me}$ tab Clin North Am 2010 Jun;39(2):365-79

72. Sun exposure rapidly reduces plasmacytoid dendritic cells and inflammatory dermal dendritic cells in psoriatic skin. Heier I, Søyland E, Krogstad AL, Rodríguez-Gallego C, Nenseter MS, Jahnsen FL. Br J Dermatol Oct;165(4):792-801

73. Effects of ultraviolet light on human serum 25-hydroxyvitamin D and systemic immune function. Milliken SV, Wassall H, Lewis BJ, Logie J, Barker RN, Macdonald H, Vickers MA, Ormerod AD. J Allergy Clin Immunol 2012 Jun;129(6):155461

74. Seasonality and autoimmune diseases: The contribution of the four seasons to the mosaic of autoimmunity. Watad A, Azrielant S, Bragazzi NL, Sharif K et al. J Autoimmun 2017 Aug;82:13-30.

75. Association between seasonal factors and multiple sclerosis. Watad A, Azrielant S, Soriano A, Bracco D et al. Eur J Epidemiol 2016 Nov;31(11):10811089.

76. Sun exposure over the life course and associa- tions with multiple sclerosis. Tremlett $\mathrm{H}, \mathrm{Zhu}$ F, Ascherio A, Munger KL Neurology 2018 Apr 3;90(14):e1191-e1199.

77. Seasonality of tuberculosis in the United States, 1993-2008. Willis MD, Winston CA, Heilig CM, Cain KP, Walter ND, Mac Kenzie WR. Clin Infect Dis 2012 Jun;54(11):1553-60

78. Seasonality of tuberculosis in Israel, 2001-2011. Margalit I, Block C, Mor Z. Int J Tuberc Lung Dis 2016 Dec 1;20(12):1588-1593

79. Influenza: The Last Great Plague W.I.B. Beveridge publ. Prodist, NY 1978

80. Global breast cancer seasonality. Oh E-Y, Ansell C, Nawaz H, Yang C-H, Wood P, Hrushesky WJM Breast Cancer Res Treat 2010 Aug;123(1):233-43.

81. Impact of season of diagnosis on mortality among breast cancer survivors. Kuzmickiene I, Atkocius V, Aleknavicius E, Ostapenko V J Cancer Res Ther 2018 Dec;14(Supplement):S1091-S1097.

82. Changes in risk of death from breast cancer with season and latitude: sun exposure and breast cancer survival in Norway. Poroinicu AC, Lagunova Z, Robsahm TE, Berg JP, Dahlback A, Moan J Breast Cancer Res Treat 2007 May;102(3):323-8.

83. Vitamin D and autoimmune diseases. Illescas-Montes R, Melguizo-Rodríguez L, Ruiz C, Costela-Ruiz VJ Life Sci 2019 Sep 15;233:116744.

84. Seasonal variations of $25-\mathrm{OH}$ vitamin D serum levels are associated with clinical disease activity in multiple sclerosis patients. Hartl C, Obermeier V, Gerdes LA, Brügel M et al. J Neurol Sci 2017 Apr 15;375:160-164.

85. Association of seasonal serum 25-hydroxyvitamin $\mathrm{D}$ levels with disability and relapses in relapsing-remitting multiple sclerosis. Brola W, Sobolewski P, Szczuchniak W, Góral A et al. Eur J Clin Nutr 2016 Sep;70(9):995-9.

86. Hypovitaminosis D association with disease activity in relapsing remitting multiple sclerosis in Brazil. Becker J, Callegaro D, Lana-Peixoto MA, Talim N et al. J Neurol Sci 2016 Apr 15;363:236-9.

87. 25-Hydroxyvitamin D levels in serum at the onset 
of multiple sclerosis. Soilu-Hänninen M, Mononen AI, Heikilä A, Viljanen M, Hänninen A Mult Scler 2005 Jun;11(3):266-71.

88. A low vitamin D status at diagnosis is associated with an early conversion to secondary progressive multiple sclerosis. Muris A-H, Rolf L, Broen K, Hupperts R et al. J Steroid Biochem Mol Biol 2016 Nov;164:254-257.

89. Environmental risk factors for multiple sclerosis: a review with a focus on molecular mechanisms. O'Gorman C, Lucas R, Taylor B Int J Mol Sci 2012;13(9):11718-52.

90. Low $25(\mathrm{OH})$ vitamin D levels are associated with autoimmune thyroid disease in polycystic ovary syndrome. Muscogiuri G, Palomba S, Caggiono M Endocrine 2016 Aug;53(2):538-42.

91. 25 Hydroxyvitamin D Deficiency and Its Relationship to Autoimmune Thyroid Disease in the Elderly. Muscogiuri G, Mari D, Prolo S, Fatti LM et al. Int J Environ Res Public Health 2016 Aug 26;13(9):850.

92. Vitamin D and Autoimmune Thyroid Disease-Cause, Consequence, or a Vicious Cycle? Vieira IH, Rodrigues D, Paiva I Nutrients 2020 Sep 11;12(9):2791.

93. Meta-analysis of the association between vitamin $\mathrm{D}$ and autoimmune thyroid disease. Wang J, Ly S, Chen G, Gao C et al Nutrients 2015 Apr 3;7(4):2485-98.

94. Vitamin D and systemic lupus erythematous: a review. Clin Exp Rheumatol Jan-Feb 2018;36(1):153162.

95. Vitamin D in lupus - new kid on the block? Kammen DL Bull NYU Hosp Jt Dis 2010;68(3):218-22.

96. Vitamin D and systemic lupus erythematosus: state of the art. Schneider L, Dos Santos ASP, Santos M, da Silva RM et al Clin Rheumatol 2014 Aug;33(8):1033-8.

97. Vitamin D level in rheumatoid arthritis and its correlation with the disease activity: a meta-analysis. Lee Y-H, Bae S-C Clin Exp Rheumatol Sep-Oct 2016;34(5):827-833.
98. Prevalence of vitamin D deficiency in rheumatoid arthritis and association with disease activity and cardiovascular risk factors: data from the COMEDRA study. Cechitti S, Tatar Z, Galan P, Pereira B et al Clin Exp Rheumatol Nov-Dec 2016;34(6):984990.

99. European multicentre pilot survey to assess vitamin D status in rheumatoid arthritis patients and early development of a new Patient Reported Outcome questionnaire (D-PRO). Vojinovic J, Tincani A, Sulli A, Soldano S et al Autoimmun Rev 2017 May;16(5):548-554.

100. Vitamin D and Sjögren syndrome. Garcia-Carrasco M, Jiménez-Herrera EA, Gálvez-Romero JL et al Autoimmun Rev 2017 Jun;16(6):587593.

101. Vitamin D treatment for connective tissue diseases: hope beyond the hype? Reynolds JA, Bruce IN Rheumatology (Oxford) 2017 Feb;56(2):178-186

102. Vitamin D and systemic lupus erythematosus - The hype and the hope. Shoenfeld Y, Giacomelli R, Azrielant S, Berardicurti O et al. Autoimmun Rev 2018 Jan;17(1):19-23.

103. Severe vitamin D deficiency is a prognostic biomarker in autoimmune hepatitis. Ebadi M, Bhanji RA, Mazurak VC, Lytvyak E et al. Aliment Pharmacol Ther 2019 Jan;49(2):173-182.

104. Vitamin D deficiency and diabetes. Berridge M Biochem J 2017 Mar 24;474(8):1321-1332.

105. Vitamin D and diabetes. Takiishi T, Gysemans C, Bouillon R, Mathieu C Endocrinol Metab Clin North Am 2010 Jun;39(2):419-46,

106. The relationship between vitamin $\mathrm{D}$ level and organ-specific autoimmune disorders in newly diagnosed type I diabetes mellitus. Akdere G, Efe B, Sisman P, Yorulmaz G Bratisl Lek Listy 2018;119(9):544-549.

107. Low levels of 25-hydroxyvitamin D in children and adolescents with type 1 diabetes mellitus: a single center experience. Bae KN, Nam H-K, Rhie Y-J, Song DJ et al. Ann Pediatr Endocrinol Metab 2018 Mar;23(1):21-27. 
108. Vitamin D and inflammatory bowel disease. Ardesia M, Ferlazzo G, Fries W Biomed Res Int 2015;2015:470805.

109. Vitamin D and Crohn's disease in the adult patient: a review. Basson A JPEN J Parenter Enteral Nutr 2014 May;38(4):438-58.

110. Vitamin D deficiency and the pathogenesis of Crohn's disease. White JH J Steroid Biochem Mol Biol 2018 Jan;175:23-28.

111. Does vitamin D play a role in autoimmune endocrine disorders? A proof of concept. Altieri B, Muscgiuri G, Barrea L, Mathieu C et al. Rev Endocr Metab Disord 2017 Sep;18(3):335-346.

112. Vitamin D endocrine system involvement in autoimmune rheumatic diseases. Cutolo M, Pizzorni C, Sulli A Autoimmun Rev 2011 Dec;11(2):84-7.

113. Seasonal variation of serum vitamin D levels in Romania. Niculescu DA, Capatina CAM, Dusceac R, Caragheorgheopol A, Ghemigian A, Poiana C. Arch Osteoporos 2017 Dec 11;12(1):113.

114. Circannual versus seasonal variations of longitudinally sampled 25-hydroxycholecalciferol serum levels. Cugini P, Coen G, Scavo D, Lucia P, Mazzaferro S, Bianchini G, Massimetti C, Donato G. Biochem Med 1984 Aug;32(1):22-9.

115. Biological Effects of Sunlight, Ultraviolet Radiation, Visible Light, Infrared Radiation and Vitamin D for Health. Holick MF Anticancer Res 2016 Mar;36(3):1345-56.

116. Ultraviolet B Radiation: The Vitamin D Connection. Holick MF Adv Exp Med Biol 2017;996:137-154.

117. Influence of season and latitude on the cutaneous synthesis of vitamin D3: exposure to winter sunlight in Boston and Edmonton will not promote vitamin D3 synthesis in human skin. Webb AR, Kline L, Holick MF. J Clin Endocrinol Metab 1988 Aug;67(2):373-8.

118. Environmental factors that influence the cutaneous production of vitamin D. Holick MF Am
J Clin Nutr 1995 Mar;61(3 Suppl):638S-645S.

119. Global Overview of Vitamin D Status. van Schoor N, Lips P. Endocrinol Metab Clin North Am Dec;46(4):845-870

120. Vitamin D deficiency and insufficiency among US adults: prevalence, predictors and clinical implications. Liu X, Baylin A, Levy PD. Br J Nutr. 2018 Apr;119(8):928-936.

121. Vitamin D deficiency in urban Massachusetts newborns and their mothers. Merewood A, Mehta SD, Grossman X, Chen TC, Mathieu JS, Holick MF, Bauchner H. Pediatrics 2010 Apr;125(4):640-7

122. Extremely High Prevalence of Maternal and Neonatal Vitamin D Deficiency in the Arab Population. Fouda MA, Turkestani IZ, Almusharraf S, Al-Ajlan A, Angkaya-Bagayawa FF, Sabico S, Mohammed AG, Hassanato R, Al-Serehi A, Alshingetti NM, Al-Daghri NM. 2017;112(3):225-230

123. Sunlight and Vitamin D: A global perspective for health. Wacker M, Holick MF Dermatoendocrinol 2013 Jan 1;5(1):51-108.

124. The Fourth Phase of Water: Beyond Solid, Liquid, Vapor Gerald H. Pollack Ebner \& Sons Publishers, 2013

125. Water structure and interactions with protein surfaces. Raschke TM. Curr Opin Struct Biol 2006 Apr;16(2):152-9

126. Water Determines the Structure and Dynamics of Proteins. Bellissent-Funel MC, Hassanali A, Havenith M, Henchman R, Pohl P, Sterpone F, van der Spoel D, Xu Y, Garcia AE. Chem Rev 2016 Jul 13;116(13):7673-97

127. Water mediation in protein folding and molecular recognition. Levy Y, Onuchic JN. Annu Rev Biophys Biomol Struct 2006;35:389-415.

128. Dynamics of hydration water in proteins. Teixeira J. Gen Physiol Biophys 2009;28(2):168-73.

129. Sub-terahertz spectroscopy reveals that proteins influence the properties of water at grea- 
ter distances than previously detected. Sushko O, Dubrovka R, Donnan RS. J Chem Phys 2015 Feb 7;142(5):055101

130. Life at the Cell and Below-Cell Level: The Hidden History of a Fundamental Revolution in Biology Gilbert Ling Pacific Press, New York (2001)

131. The role of water in amyloid aggregation kinetics. Stephens AD, Kaminski Schierle GS. Curr Opin Struct Biol 2019 Oct; 58:115-123

132. Local structure and dynamics of hydration water in intrinsically disordered proteins. Rani P, Biswas P J Phys Chem B 2015 Aug; 119(34): 10858-67

133. Interaction with surrounding water plays a key role in determining the aggregation propensity of proteins. Chong SH, Ham S Angew Chem Int Ed Engl 2014 Apr: 53(15):1961-4

134. Protein structural and surface water rearrangement constitute major events in the earliest aggregation stages of tau. Pavlova A, Cheng CY, Kinnebrew M, Lew J, Dahlquist FW, Han S Proc Natl Sci USA 2016 Jan; 113(2):E127-36

135. Role of water in aggregation and amyloid polymorphism. Thirumalai D, Reddy G, Straub JE Acc Chem Res 2012 Jan; 45(1):83-92

136. Biology of Bilirubin Photoisomers. Hansen TW. Clin Perinatol. 2016 Jun;43(2):277-90

137. Vitamin D Receptor: New Assignments for an Already Busy Receptor. Norman AW. Endocrinology 2006; vol 147: pp. 5542-5548

138. Vitamin D and inflammation. Cannell JJ, Grant WB, Holick MF Dermatoendocrinol 2015 Jan 29;6(1):e983401. MIXED RESULTS

139. Vitamin $\mathrm{D}$ for the management of multiple sclerosis. Jagannath VA, Filippini G, Di Pietrantoni C, Asokan GV et al. Cochrane Database Syst Rev 2018 Sep 24;9(9):CD008422.

140. Vitamin D for the management of multiple sclerosis. Jagannath VA, Fedorowicz Z, Asokan GV Robak EW, Whamond L Cochrane Database Syst Rev 2010 Dec 8;(12):CD008422
141. The activation of the cytochrome P-450 dependent monooxygenase system by light. Müller-Enoch D, Gruler H. Z Naturforsch C 1986 May-Jun;41(5-6):604-12

142. Light-induced activation and synchronization of the cytochrome P-450 dependent monooxygenase system. Häberle W, Gruler H, Dutkowski P, Müller-Enoch D. Z Naturforsch C 1990 Mar-Apr;45(3-4):273-9

143. Light-driven biocatalysis with cytochrome P450 peroxygenases. Girhard M, Kunigk E, Tihovsky S, Shumyantseva VV, Urlacher VB. Biotechnol Appl Biochem 2013 Jan-Feb; 60(1): 111-18

144. Slaving the cytochrome P-450 dependent monooxygenase system by periodically applied light pulses. Gruler H, Müller-Enoch D. Eur Biophys J 1991; 19(4): 217-19

145. Extrarenal expression of 25-hydroxyvitamin d(3)-1 alpha-hydroxylase. Zehnder D, Bland R, Williams MC, McNinch RW et al. J Clin Endocrinol Metab 2001 Feb;86(2):888-94.

146. Extrarenal expression of the 25-hydroxyvitamin D-1-hydroxylase. Adams JS, Hewison M Arch Biochem Biophys 2012 Jul 1;523(1):95-102.

147. Expression of 25-hydroxyvitamin D-1alpha-hydroxylase (1alphaOHase, CYP27B1) splice variants in $\mathrm{HaCaT}$ keratinocytes and other skin cells: modulation by culture conditions and UV-B treatment in vitro. Seifert M, Tilgen W, Reichrath J Anticancer Res 2009 Sep;29(9):3659-67.

148. Biologically Closed Electric Circuits Björn Nordenström Nordic Publications 1983

149. A brief history of the study of nerve dependent regeneration. Farkas JE, Monaghan JR Neurogenesis 2017 Apr 10;4(1):e13022

150. Trophic functions of the neuron. VI. Other trophic systems. Neurotrophic control of limb regeneration in the newt. Singer M, Ann. N. Y. Acad. Sci 1974; 228, 308-322.

151. On the Nature of the Neurotrophic Phenome- 
non in Urodele Limb Regeneration. Singer M, Integr. Comp Biol 1978; 18, 829-841.

152. The role of peripheral nerves in urodele limb regeneration. Slocum DL Eur J Neurosci 2011 Sep;34(6):908-16.

153. The nerve dependence of amphibian limb regeneration. Brockes JP J Exp Biol 1987 Sep;132:79-91

154. Nerve dependence in tissue, organ, and appendage regeneration. Kumar A, Brockes JP Trends Neurosci 2012 Nov;35(11):691-9

155. Spinal cord is required for proper regeneration of the tail in Xenopus tadpoles. Taniguchi Y, Sugiura T, Tazaki A, Watanabe K, Mochii M Dev Growth Differ 2008 Feb;50(2):109-20.

156. Le probleme morphogenetique dans le regeneration des Urodeles: determination et potentialites des regenerats. Guyenot E. Rev Suisse de Zoologie 1927; (34): 127-54

157. Lexploration du territoire de la patte anterieure du Triton. Guyenot E, Dinichert-Favarger J, Galland M Rev Suiise de Zoologie 1948; 00:1120

158. Preconditioning with ischemia: a delay of lethal cell injury in ischemic myocardium. Murry CE, Jennings RB, Reimer KA. Circulation. 1986 Nov;74(5):1124-36.

159. A "second window of protection" occurs $24 \mathrm{~h}$ after ischemic preconditioning in the rat heart. Yamashita N, Hoshida S, Taniguchi N, Kuzuya T, Hori M. J Mol Cell Cardiol 1998;30(6):1181-9

160. Ischemic preconditioning: from the first to the second window of protection. Pagliaro P, Gattullo D, Rastaldo R, Losano G. Life Sci 2001 May 25;69(1):1-15.

161. Organ preconditioning. Raeburn CD, Cleveland JC Jr, Zimmerman MA, Harken AH Arch Surg 2001 Nov;136(11):1263-6.

162. Review of remote ischemic preconditioning: from laboratory studies to clinical trials. Anttila V, Haapanen H, Yannopoulos F et al Scand Cardiovasc J Oct-Dec 2016;50(5-6):355-361.
163. The neural and humoral pathways in remote limb ischemic preconditioning. Lim SY, Yellon DM, Hausenloy DJ. Basic Res Cardiol 2010 Sep;105(5):651-5

164. Effect of denervation and ischemia reperfusion injury on serum nitric oxide levels in rats. Ozsoy U, Mutluay R, Oygur N, Akbas H, Sindel S, Sindel M. Saudi Med J 2008;29(11):1561-6

165. Cerebral blindness. Flanagan C, Kline L, Curè J Int Ophthalm Clin 2009; 49(3): 15-25

166. Acute cortical blindness caused by pre-eclampsia in the antepartum: posterior reversible encephalopathy syndrome (PRES). Yacong W, Qinying C, Lihong Z et al. Afr Health Sci 2015; 15(2): 705-708

167. Bilateral middle cerebral artery haemorrhagic infarcts presenting only as cortical blindness. Das A, Anand S Postgrad Med J 2019; 95(1122): $227-28$

168. Biologically Closed Electric Circuits pp. 81-82

169. Beyond the Moon: A Conversational, Common Sense Guide to Understanding the Tides. James Greig McCully publ. World Scientific 2006

170. Tree stem diameters fluctuate with tide. Zürcher E, Cantiani M-G, Sorbetti-Guerri F, Michel D. Nature 1998; 392: 665-666.

171. The primal integrated realm and the derived interactive realm in relation to biosemiosis, and their link with the ideas of J.W. von Goethe. Barlow PW Communicative \& Integrative Biology 2012; 5: 434-439.

172. Lunisolar tidal force and the growth of plant roots, and some other of its effects on plant movements. Barlow PW, Fisahn J Annals of Botany 2012; 110: 301-318.

173. Tree-stem diameter fluctuates with the lunar tides and perhaps with geomagnetic activity. Barlow PW, Mikulecký M, Streštík J Protoplasma 2010; 247: 25-43

174. Do tree stems shrink and swell with the tides? Vesala T, Sevanto S, Paatero P et al. Tree Physio$\log y$ 2000; 20: 633-635. 
175. An Electro-Dynamic Theory of Development Suggested by Studies of Proliferation Rates in the Brain of Amblystoma. Burr HS, Journal of Comparative Neurology, 1932; 56: 347-371

176. The Electro-Dynamic Theory of Life. Burr HS, Northrop, FSC Quarterly Review of Biology 1935; 10: 322-333

177. Electrical Characteristics of Living Systems. Burr HS, Northrop, F. S. C. Yale Journal of Biology and Medicine, 1935; 8: 31-3

178. A Vacuum Tube Micro-voltmeter for the Measurement of Bio-electric Phenomena. Burr HS, Lane, CT, Nims, LF, Yale Journal of Biology and Medicine 1936; 10: 65-76

179. Bio-Electric Potential Gradients in the Chick. Burr HS, Hovland, CI Yale Journal of Biology and Medicine 1937; 9: 247-258.
180. Evidence for the Existence of an Electro-Dynamic Field in Living Organisms. Burr HS, Northrop, FSC Proceedings National Academy of Science 1939; 25: 284-288.

181. Controlling Cell Behavior Electrically: Current Views and Future Potential. McCaig CD, Rainicek AM, Song B, Zhao M Physiol Rev 2005; 85: 943-978

182. Xenopus tadpole tail regeneration requires the activity of the proton pump V-ATPase, and proton pumping is sufficient to partially rescue the loss of function phenotype. Adams DS, Masi A, Levin M. Dev Biol. 2006;295:355-356.

183. $\mathrm{H}+$ pump-dependent changes in membrane voltage are an early mechanism necessary and sufficient to induce Xenopus tail regeneration. Adams DS, Masi A, Levin M. Development. 2007;134:1323-1335. 